\title{
EL VIOLÓN DE DOMINGO ROMÁN (VALLADOLID, 1724)
}

Pedro Reula Baquero

Conservatorio Profesional Federico Moreno Torroba, de Madrid

(Asesoría técnica: Robert Louis Baille)

\begin{abstract}
Resumen:
El violón de Domingo Román (V alladolid, 1724) viene a enriquecer la escasa nómina de instrumentos de arco españoles conservados del siglo XVIII. Este artículo pretende ser, básicamente, una presentación y descripción del violón. El análisis del contexto estilístico trata de poner en relación sus peculiares características constructivas con las de la escuela española de los violeros de los siglos XVI a XVIII y con otras europeas como la flamenca y alemana.
\end{abstract}

Palabras clave:

Violón; violonchelo; violero; vihuela de arco; Domingo Román; Gabriel de Murcia; Valladolid

\section{Abstract}

Domingo Roman's cello is one of the $\mathrm{v}$ ery few surviving Spanish bo wed instruments from the eighteenth century . This article basically pretends to present and describe this recently rediscovered instrument by analising it's very peculiar way of construction, comparing it with the informations we have about the Spanish school of making from sixteen till eighteenth century and other contemporary schools like the flamish and the german one.

Key words:

Bass violin; violoncello; cello builder; viola da gamba; Domingo Román; Gabriel de Murcia; Valladolid

\section{INTRODUCCIÓN}

Cualquier nuevo dato sobre la historia del violonchelo en España es bien recibido. Más lo es que aparezca un instrumento del siglo XVIII perteneciente, en parte, a la antigua escuela de los violeros españoles. Esperamos que el "nuevo" violón de Domingo Román aporte un poco de luz sobre la historia de nuestro patrimonio musical.

A pesar de que existen ciertas dificultades y dudas para saber a qué se referían los españoles de los siglos XVI a XVIII cuando hablaban del violón (o biolon), hay un consenso general en llamar 
violones a los instrumentos de la f amilia del violín, esto es, los instrumentos de cuerda frotada con cuatro cuerdas af inadas por quintas y sin trastes en contraposición a las vihuelas de arco, con seis cuerdas af inadas por cuartas y con trastes. Así lo podemos encontrar en los principales tratadistas españoles como Nasarre y en el diccionario de Covarrubias. Antes de la diferenciación terminológica de los distintos instrumentos de la $\mathrm{f}$ amilia, se designaba a todos como violones ${ }^{1}$ $\mathrm{y}$, en función de su re gistro, tiple, contralto, bajo, contrabaxo o violón grande ${ }^{2}$. Aunque el de Domingo Román es, por sus proporciones, un violonchelo y no un bajo de violín $\quad{ }^{3}$, mantiene numerosas características de la técnica de construcción de los violeros y guitarreros españoles anteriores a la asunción internacional de las técnicas italianas. Por esta razón y por usar el término español, lo llamaremos violón.

No va a ser este un artículo generalista en el que ayamos a hablar de los violones y las vihuelas de arco en la España. Intentaremos, no obstante, ponerlo en su conteto, tanto español como internacional, para poder hacer un mejor análisis. Por esto, dejamos para una ocasión futura entrar en el debate y profundización en torno al tema de la terminología de los instrumentos de cuerda frotada en España e Iberoamérica. Para ello remitiremos a los estudios clásicos sobre el tema ${ }^{4}$. Hay un término, aparecido en el Diario de Madrid5", que sí que nos gustaría, cuando menos, citar. Se trata del "violón de capilla", instrumento que, si bien se podría diferenciar de un supuesto "violón de cámara", no alcanzamos, de momento, a identificar.

\section{Domingo Román, Valladolid, 1724}

Hasta la fecha, la única referencia bibliográfica referente al violón de Domingo Román era la siguiente de Cristina Bordas:

1 RoBledo, Luis: "Vihuelas de arco y violones en la corte de Felipe III", en Actas del Congreso Internacional "España en la Música de Occidente”. Madrid, INAEM, 1987, vol. 2, pp. 63-76.

2 Para el término violón grande, ver GonZÁlez MARín, Luis Antonio: Música para los ministriles de El Pilar de Zaragoza (16711672). Vol. i de PiezAs de Musica. Zaragoza, IFC, 1991; GonZÁlez Marín, Luis Antonio: "Aportación al conocimiento de la terminología musical española en el siglo XVII: El Madrigal considerado como composición para instrumentos”, en Nassarre, 5/2 (1989), p. 126.

3 Cuando hablamos de bajo de violín nos referimos a un instrumento más grande que el violonchelo, afinado por cuartas y que, de cuatro o cinco cuerdas, puede estar afinado en Si bemol o en Do. Ver la siguiente nota, fundamentalmente los artículos de Stephan Bonta y Stefano La Via.

4 Robledo, Luis: "V ihuelas de arco y violones en la corte de Felipe III", op. cit., pp. 63-76; G Ándara, Xosé Crisanto: "El violón ibérico", en Revista de Musicología, XXII/2 (1999), pp. 123-163; Aspectos de la cultura musical en la Corte de Felipe II. Luis Robledo Estairé, Tess Knighton, Cristina Bordas Ibáñez, Juan José Carreras, eds., Madrid, Fundación Caja Madrid (Colección Patrimonio Musical Español), 2000; ANDRÉs, Ramón: Diccionario de instrumentos musicales. Desde la antigüedad hasta Bach. Barcelona, Península, 2001, pp. 471-472; B ONTA, Stephan: Studies in Italian Sacred and Instrumental Music in the $17^{\text {th }}$ Century. Ashgate Publishing, 2003; "Corelli's Heritage: The early bass violin in Italy", en Studi Corelliani IV. Firenze, L. S. Olschki 1990, pp. 217-231; "Terminology for the Bass Violin in the Seventeenth-Century Italy", en Journal of the American Musical Instrument Society, IV (1978), pp. 5-42; LA VIA, Stefano: "Violone e violoncello a Roma al tempo di Corelli.Terminologia, Modelli organologici, tecniche esecuti ve", en Studi Corelliani IV. Florencia, L. S. Olschki 1990, pp. 165-191; B AINES, Francis: "What Exactly Is a Violone?: A Note towards a Solution", en Early Music, 5/2 (1977), pp. 173-176.

5 Noticia aparecida el 12.07.1758.Ver: Acker, Yolanda (recop. e índices):Música y danza en el Diario de Madrid. Noticias, avisos y artículos. 1758-1808. Madrid, INAEM, 2007, p. 22. 
"El paso hacia la "italianización" se advierte en la plantilla y acabado e xterior de otro violoncello, firmado por Domingo Román (V alladolid, 1724) y ho y en una colección pri vada en Bilbao, aunque todavía mantiene los aros incrustados en el zoque. Esta técnica ya desaparece en las obras de la segunda mitad del siglo, en que los constructores adoptan las técnicas italianas trabajadas por cada autor seún su estilo personal $[\ldots]^{\prime \prime}$.

Hoy en día el instrumento, tras habérsele perdido la pista, ya no forma parte de la citada colección privada de Bilbao pero sigue en manos particulares.

Exceptuando la vihuela de arco anónima del Con vento de la Encarnación de Ávila ${ }^{7}$, el resto de los violones o violonchelos del sigloxviII conservados tienen etiquetas, firmas o atribuciones a violeros conocidos por fuentes documentales. Así, de Gabriel de Murzia ${ }^{8}$, constructor del instrumento más cercano en características y época al de Domingo Román, se conocen algunos datos sobre su vida. Por el momento, y a la espera de encontrar documentación, el violero que ahora nos ocupa es un completo desconocido.

Se conocen datos y noticias de una importante cantidad de violeros y guitarreros de los siglos XVII y XVIII de los que no se ha conserv ado ningún instrumento pero, casualidad, no se sabe nada del constructor de uno de los escasos violones que han sobreivido. La fecha inscrita en la etiqueta impresa dice:

Domingo Román, en Valladolid, 17248

A continuación del texto impreso podemos ver un 8 escrito a mano y que podría ser una corrección de la fecha — en este caso sería de 1728 — o, siguiendo la tradición de muchos luthieres, un número de catálogo o de serie, o sea, el octavo de los instrumentos construidos por Domingo Román. Más allá de los datos ofrecidos por el propio instrumento y su etiqueta, nada sabemos de este violero.

Sí que podemos, sin embago, seguir una pista referente al salario diario cobrado por los miembros del gremio de guitarreros de Valladolid en el año de 1752, encontrada en el Catastro del Marqués de la Ensenada y publicada por varios investigadores:

Valladolid: "Guitarreros. Gerónimo Montes, dos reales; Francisco Román, quatro reales; Sebastián Balcazar, un real; el expresado Domingo Fernández, dos reales y medio"”.

6 Bordas, Cristina: "T radición e inno vación en los instrumentos musicales", en La música en España en el siglo xVIII. Coord. por Juan José Carreras, Malcom Boyd, AKAL, 2000, p. 214.

7 Ver PÉrez Arroyo, Rafael: "Una vihuela de arco y un bajón del Con vento de la Encarnación de Ávila", en Revista de Musicología, III (1980), pp. 235-259; Ver también Las edades del hombre. León, Las edades del hombre, 1992.

8 Jambou, Louis: "La lutherie à Madrid à la fin du xvire siècle", en Revista de Musicología, 9/2 (1986), pp. 427-452; Bordas, Cristina: "De violero a guitarrero: la actividad del gremio de violeros de Madrid (ca. 1577-ca. 1808)", en Estudios sobre la vihuela. Madrid, Sociedad de la vihuela, 2007, p. 136; Bordas, Cristina: Instrumentos musicales en colecciones españolas. Vol. 1. Museos de Titularidad Estatal. Madrid, Ministerio de Educación y Cultura, 1999, p. 178.

9 Bennassar, Bartolomé: Valladolid, 1752. Madrid, Centro de Gestión Catastral y Cooperación Tributaria, Ministerio de Economía y Hacienda, 1990, p. 206; R omanillos Vega, José: The Vihuela de Mano and the Spanish Guitar. A Dictionary of the Makers of Plucked and Bowed Musical Instruments of Spain (1200-2002) String Makers, Shops, Dealers \& Factories . Guijosa, 
Realmente no es mucho pero, por lo menos, sabemos que en Valladolid había un guitarrero o violero, que viene a ser lo mismo en el siglo XVIII en España, con el mismo apellido. Sabiendo de la tradición familiar asociada a los gremios creo que podemos aenturarnos a suponer un parentesco entre Domingo Román ( $f$ l. 1724) y Francisco Román ( $f$. 1752).

Queda pendiente, por tanto, un estudio de las fuentes documentales que nos den alguna noticia sobre estos dos violeros deValladolid. Mientras, no podremos datarlo definitivamente en 1724 y afirmar rotundamente que el violón haya salido de sus manos.

\section{DESCRIPCIÓN}

Además de constituir, según todos los indicios, un raro ejemplar de los instrumentos de arco construidos en España en el siglo XVIII, el violón de Domingo Román tiene la particularidad de conservarse prácticamente en su estado original. Y decimos prácticamente porque, en realidad, sí que parece haber sido reparado en algún momento, quizá a finales del siglo XIX, época en la que estaba de moda coleccionar instrumentos antiguos, tanto de tradición europea como de otras culturas, y en la que se forman una buena parte de las grandes colecciones que ho y conocemos ${ }^{10}$. Nos gustaría pensar que quizá pudo haber caído en manos de uno de esos coleccionistas ya que las reparaciones son extremadamente respetuosas con el aspecto y las características del propio violón así como con las de la época en que fue construido.

La tapa armónica está formada por cuatro piezas de pinabete y tiene una bóv eda bastante elevada. El ala derecha de la parte inferior , también de pinabete, pertenece a una reforma posterior.

Igualmente, la efe izquierda tiene una pequeña pieza repuesta.

Las efes, muy abiertas y rectas, no son simétricas, siendo más alta la izquierda.

La barra armónica, en forma de media luna y más corta de lo habitual — $30 \mathrm{cms}$. — está tallada en la misma pieza de la tapa.

Las esquinas son muy puntiagudas, con el objeto de consolidar las juntas de las piezas de la caja, ya que, posiblemente, los aros están insertados en las ranuras de la trasera.

Los bordes de la tapa sobrepasan los aros y parecen haber sido afilados en una reforma posterior.

En el hombro superior derecho hay una raja cerrada con dos tacos. Igualmente, la tapa está cerrada con tacos de distintas reformas. Esto hace pensar en la mano de un guitarrero.

\footnotetext{
Sanguino, 2002; RuIz GiméNEz, Juan: "Radiografía socioprofesional de los oficios musicales en el siglo xviII", en Música y cultura urbana en la Edad Moderna . Eds: Andrea Bombi, Juan José Carreras, Miguel Ángel Marín. Valencia, Universitat de València, 2005, p. 150; I NSARRALDE, Lidia: "Los guitarreros españoles en la primera mitad del siglo XVIII: la vida de la corporación y la transmisión del saber”, en Revista de Musicología, XXVIII/1 (2005), p. 353.

10 Ver Musique, Images, Instruments. París, Revue Française d'Organologie et d'Iconographie Musicale, $2007, \mathrm{n}^{\circ} 9$.
} 
No presenta filetes pero sí unas ranuras grabadas y teñidas de ne gro que los imitan. La pieza repuesta del ala derecha inferior respeta este filete grabado.

No conserva el puente original pero se aprecian sombras de un puente a 43,5 y a $44 \mathrm{cms}$. del borde de la tapa del mango.

Los aros son de arce de muy buena calidad y se montaron sin molde. Están cepillados y doblados con hierros candentes aunque no presentan señales de quemaduras.

Las esquinas están cerradas en el interior con tiras de lino o cáñamo y no tienen tacos de refuerzo.

El cordal está atado por una cuerda de tripa a un botón de nogal insertado en la junta de las dos piezas inferiores de los aros. P ara refuerzo interno está forrado de lino y , como decoración, presenta dos círculos concéntricos grabados.

La cuerda de tripa que ata el cordal al botón apo ya sobre un taco triangular de nogal y la veta es horizontal, paralela a las tapas, en lugar de vertical.

La trasera está compuesta de tres piezas irregulares -posiblemente debido a la escasez de madera para construirla- de chopo o álamo. La pieza más pequeña está dispuesta a modo de ala en el lado derecho inferior y está reforzada, en el interior, con una tira de lino o cáñamo.

Igualmente, la trasera está unida a los aros con lino o cáñamo como refuerzo y no tiene contraaros. La única interv ención que se ha hecho al cuerpo de la caja ha sido limpiarlo y pe gar las piezas que estaban despegadas además de cerrar una pequeña raja abierta en el hombre derecho ${ }^{11}$.

El mástil presenta una de las características más peculiares del instrumento. Al igual que las guitarras y a modo de zoque, está hecho todo de una pieza: el clavijero, el mango y el taco interno que apoya directamente sobre la trasera. Los aros no un pegados al taco sino que se insertan en dos ranuras abiertas en los laterales del mismo.

Entre el mástil y el batidor hay una cuña de pino, quizá de origen, para ele var el escaso ángulo con la caja.

No es fácil determinar la madera del mástil pero podría tratarse, al igual que la trasera, de chopo o álamo. En cualquier caso es de una madera clara y bastante blanda. Presenta un trabajo tosco y es considerablemente corto.

Igualmente tosco en su talla es el cla vijero que conserva sus cuatro agujeros originales de gran sección. Se asemeja al clavijero de una viola da gamba.

El batidor es muy corto y está hecho de nogal macizo. Presenta, como decoración, una serie de planchas de hueso dispuestas longitudinalmente y en el centro.

En cuanto a las grandes clavijas, la primera parece de una madera oscura y distinta al resto que no hemos logrado identificar y es posible que sea de la reforma posterior. El resto de las clavijas parecen ser de roble. La cuarta está hecha a partir de una rama.

11 Robert Louis Baille hizo la limpieza, consolidación y montaje del violón durante la prima vera de 2009 en su taller de Málaga. Fue expuesto en el II Encuentro Europeo de Luthiers y Músicos Ciudad de Málaga 2009. 
El cordal, igual que el batidor, es de nogal y tiene un filete de hueso o marfil donde apoyan las cuerdas. Pero, posiblemente, pertenece de la reforma posterior ya que es un nogal distinto, más claro, y la talla parece más moderna. Aún así, es muy respetuoso con el estilo el instrumento.

Sobre la trasera, los aros y el mástil se ha aplicado una especie de goma laca. No parece que sea de origen.

$\underline{\text { Medidas }}$

Longitud de la caja: fondo $76 \mathrm{cms}$. - tapa $77 \mathrm{cms}$.

Ancho superior: fondo $35 \mathrm{cms}$. - tapa $35 \mathrm{cms}$.

Ancho centro: fondo $23 \mathrm{cms}$. - tapa $22 \mathrm{cms}$.

Ancho inferior: fondo 41'5 cms. - tapa $42 \mathrm{cms}$.

Distancia del borde superior de la tapa al corte de la efe izda.: 41'2 cms.

Distancia del borde superior de la tapa al corte de la efe dcha.: 41' $5 \mathrm{cms}$.

Distancia del borde superior de la caja a la cejilla: $25^{\prime} 5 \mathrm{cms}$.

Tiro: $68 \mathrm{cms}$.

Altura de los aros: junto al talón: 12’3 cms. - en el centro: 11'7 cms. -abajo: 11'7 cms.

Distancia entre las efes: 9' $5 \mathrm{cms}$.

Longitud del batidor: 41' $6 \mathrm{cms}$. 


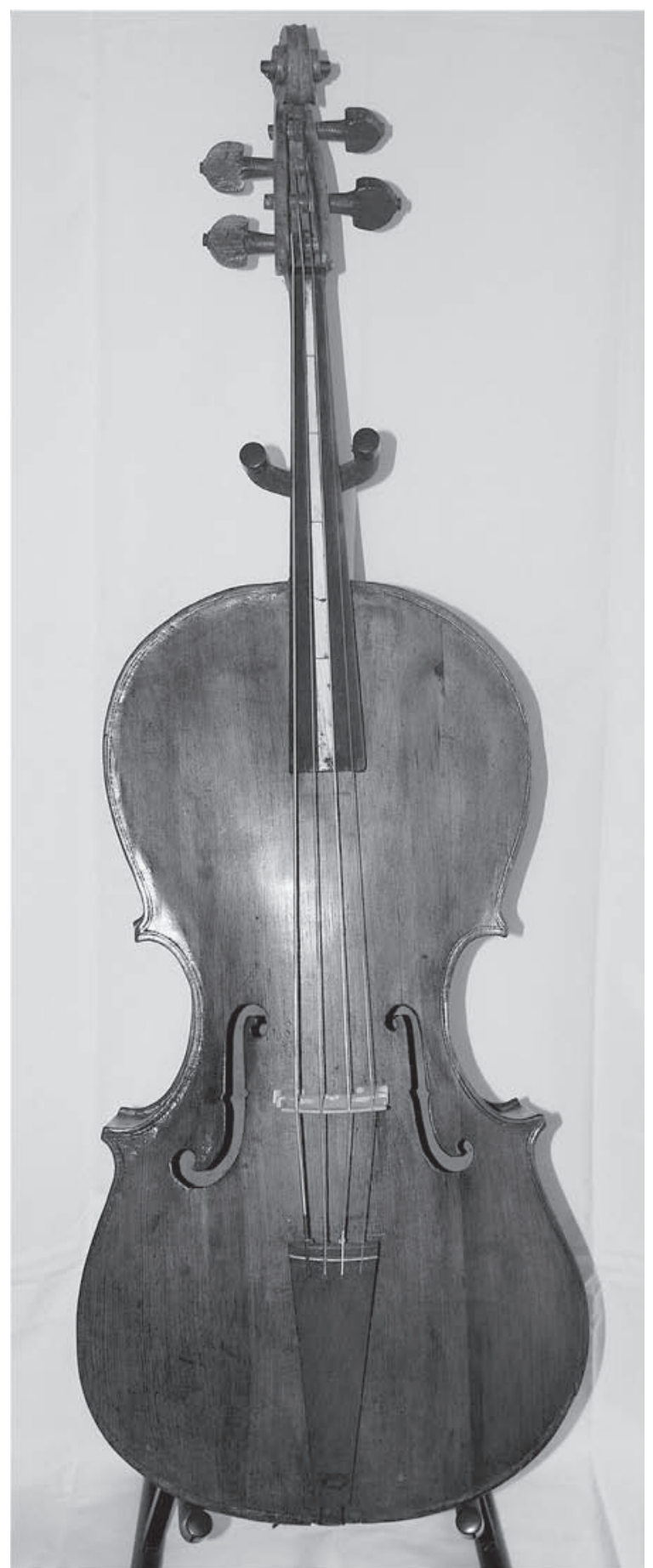

Figura 1. Violón de Domingo Román (Valladolid, 1724). 


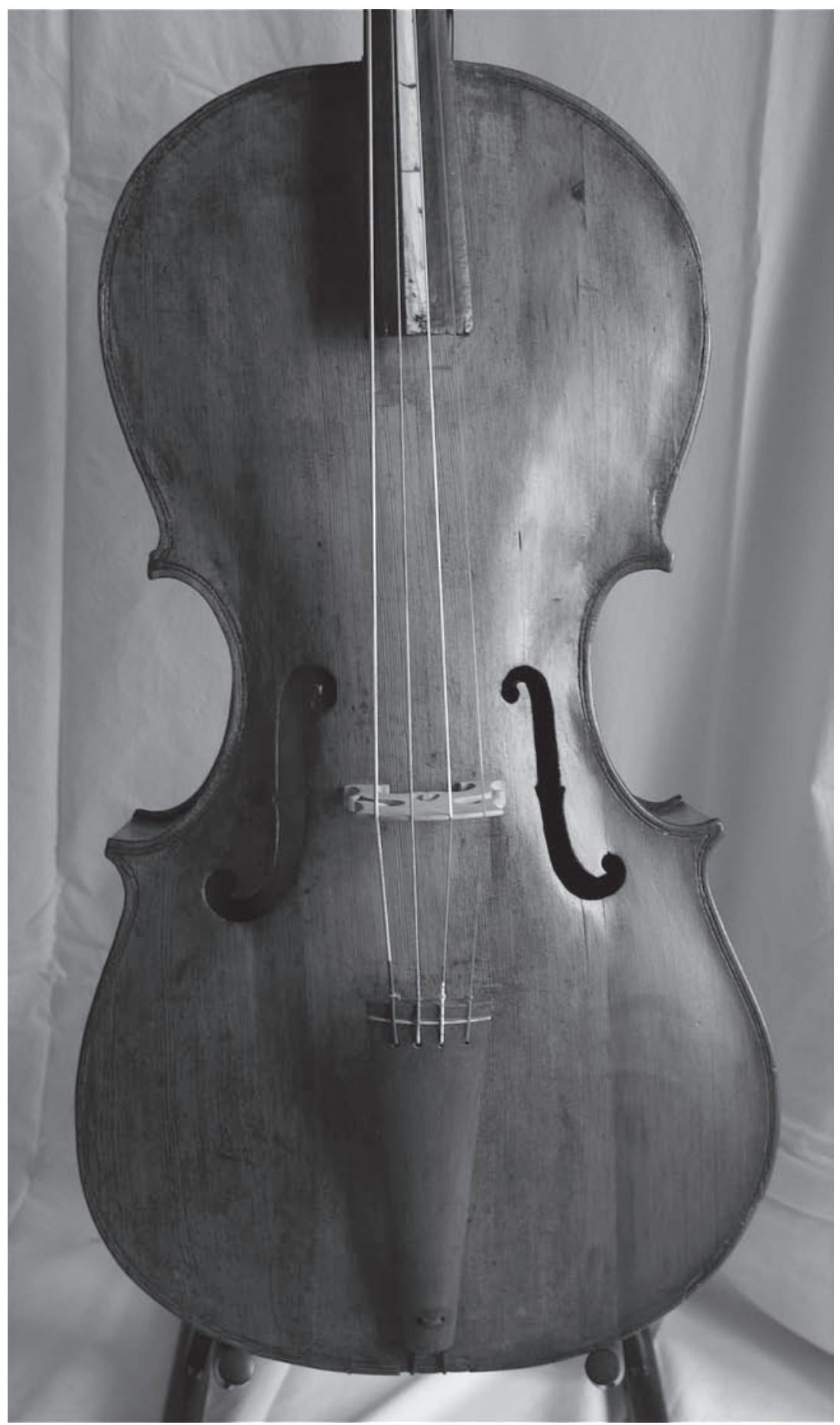

Figura 2. Tapa. 


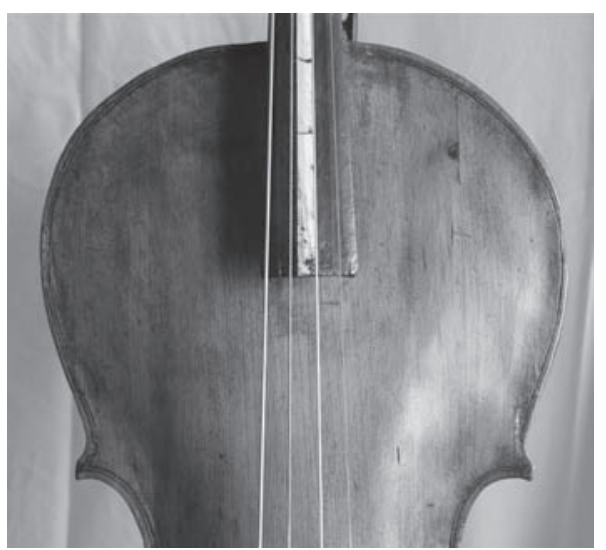

Figura 3. Detalle de los hombros.

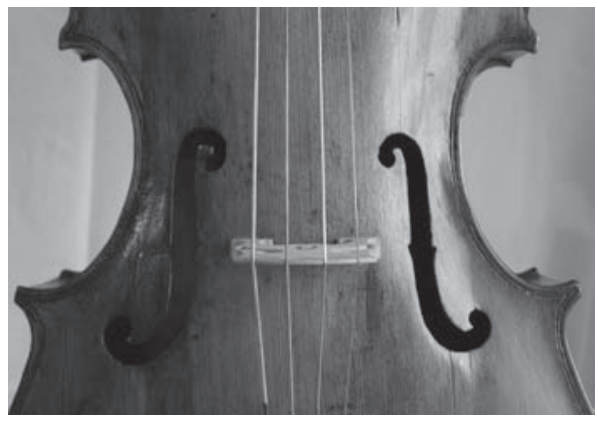

Figura 4. Centro de la tapa y efes.

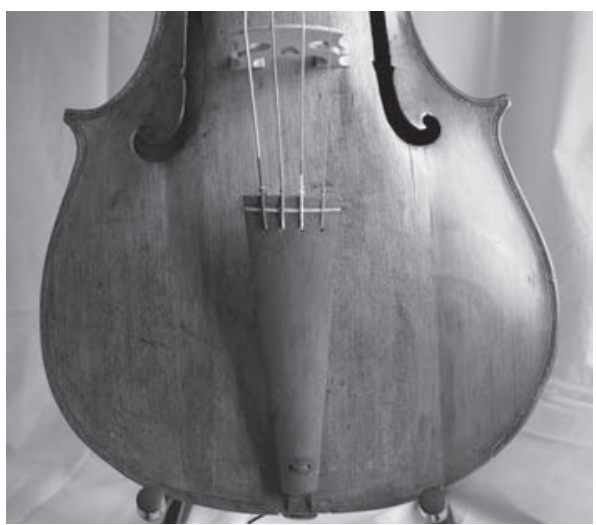

Figura 5. Detalle inferior de la tapa. 


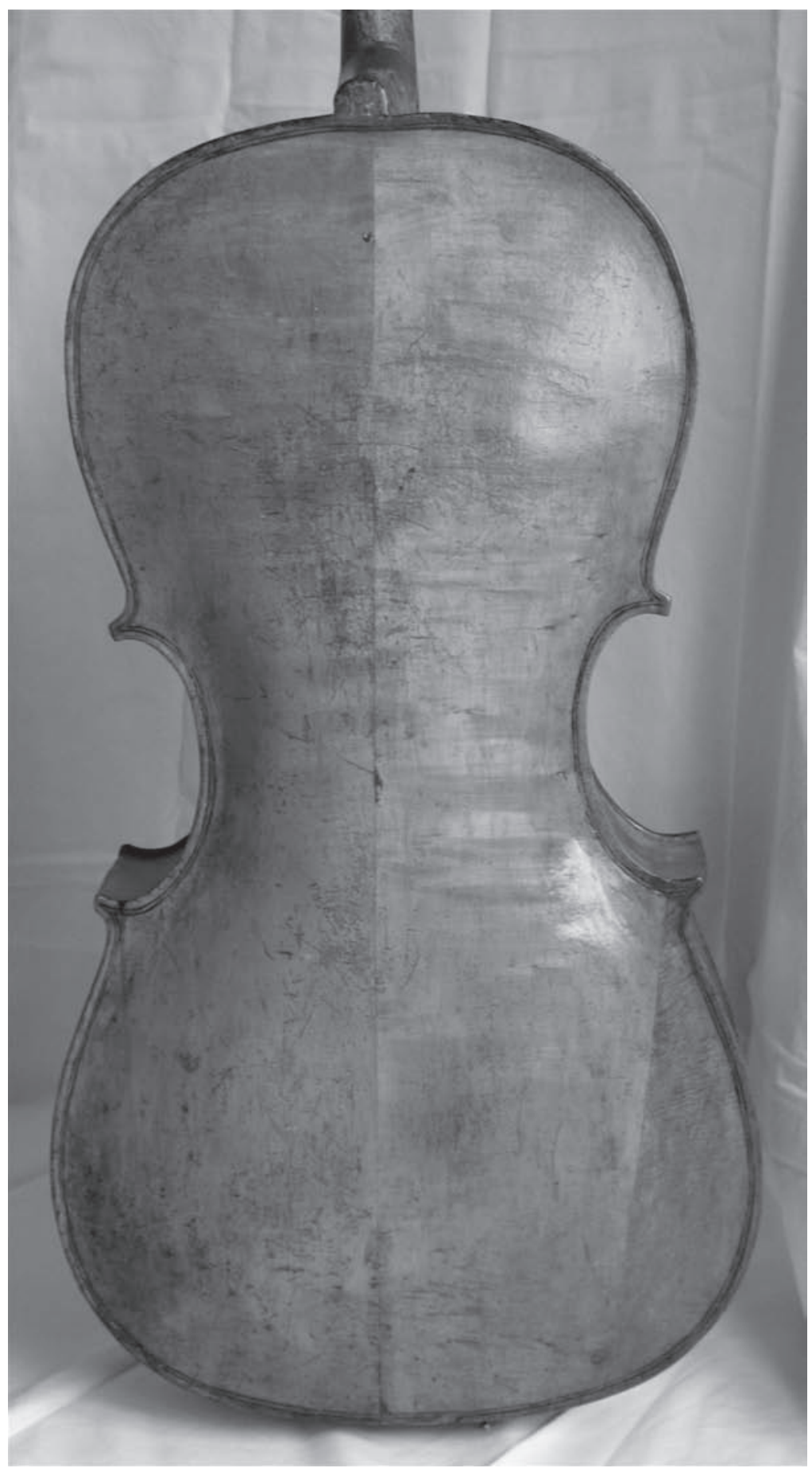

Figura 6. Trasera. 


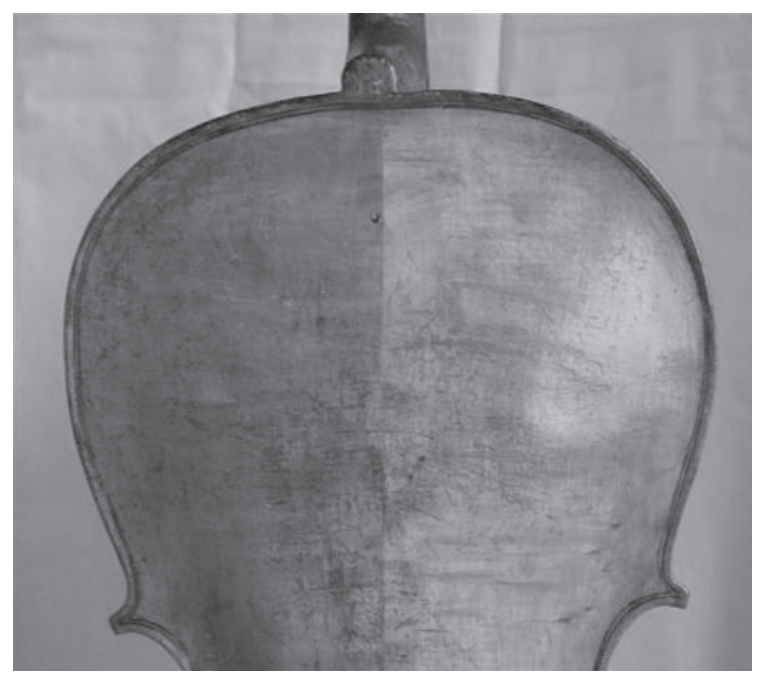

Figura 7. Hombros de la trasera.

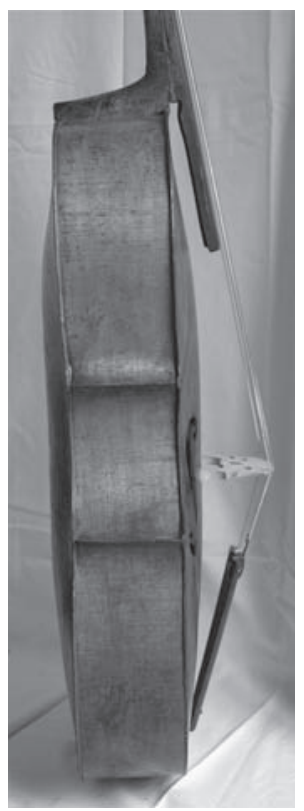

Figura 9. Aros izquierda.

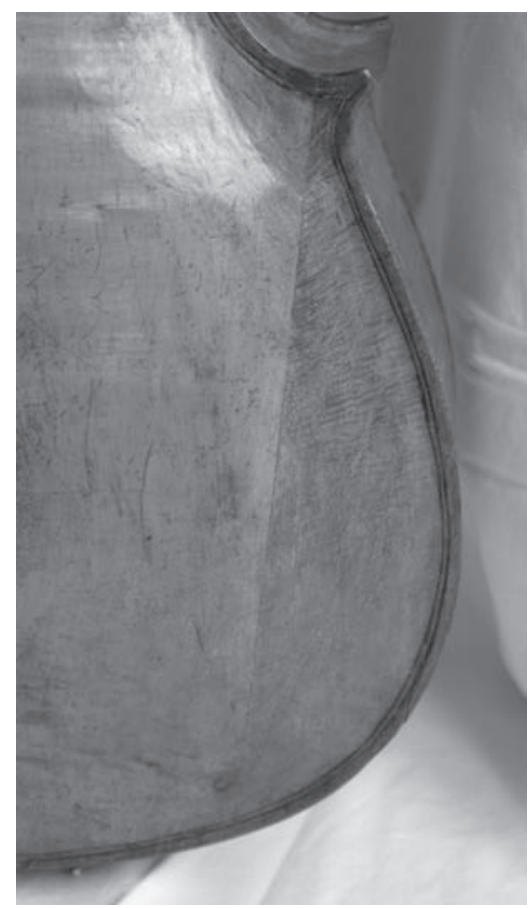

Figura 8. Detalle inferior de la trasera.

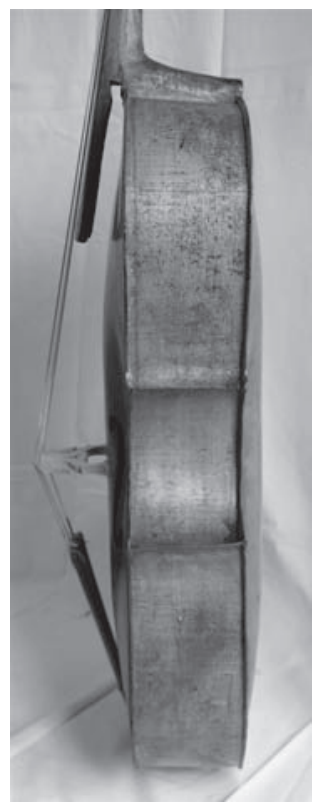

Figura 10. Aros derecha. 


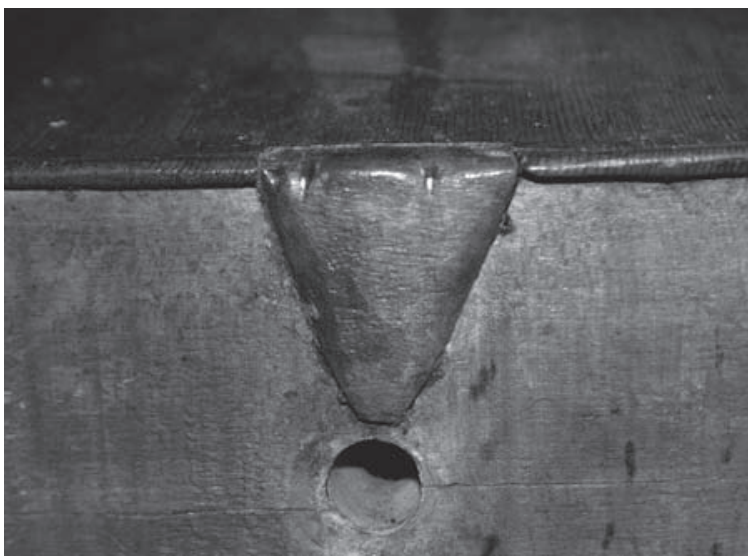

Figura 11. Detalle de los aros y taco del cordal.

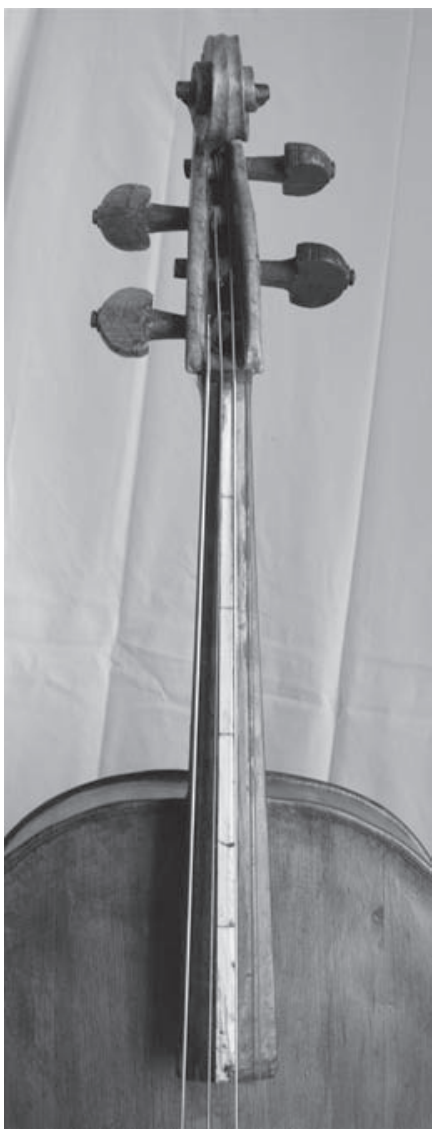

Figura 13. Mástil.

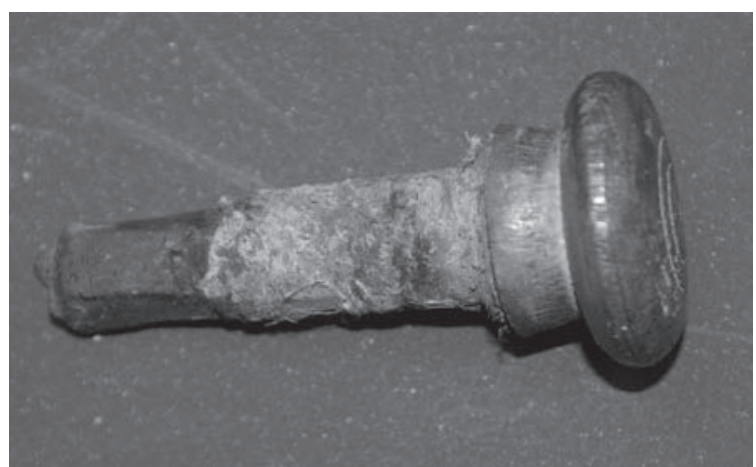

Figura 12. Botón.

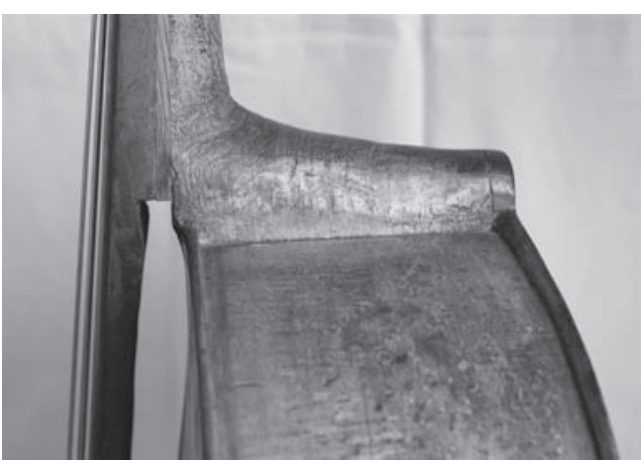

Figura 14. Taco del mástil.

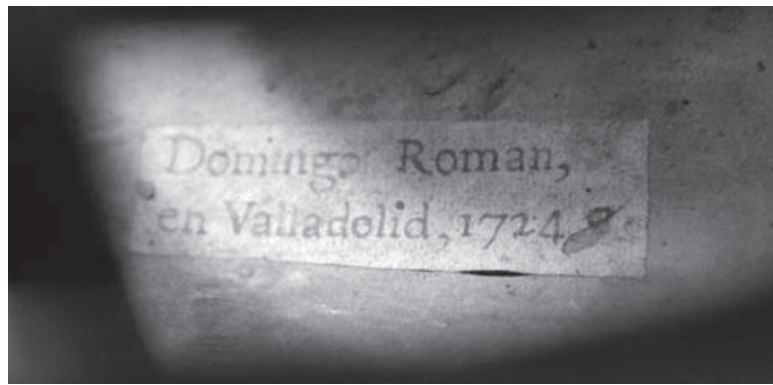

Figura 15. Etiqueta. 


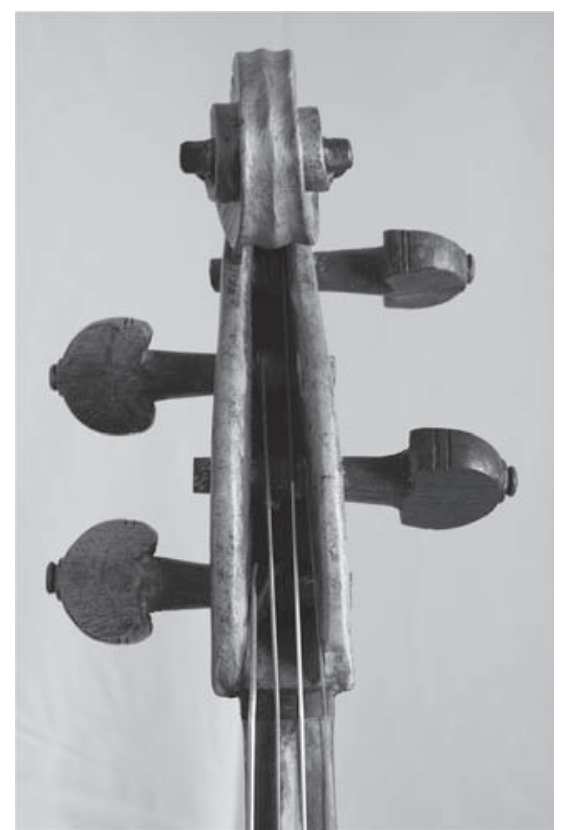

Figura 16. Frente del clavijero.

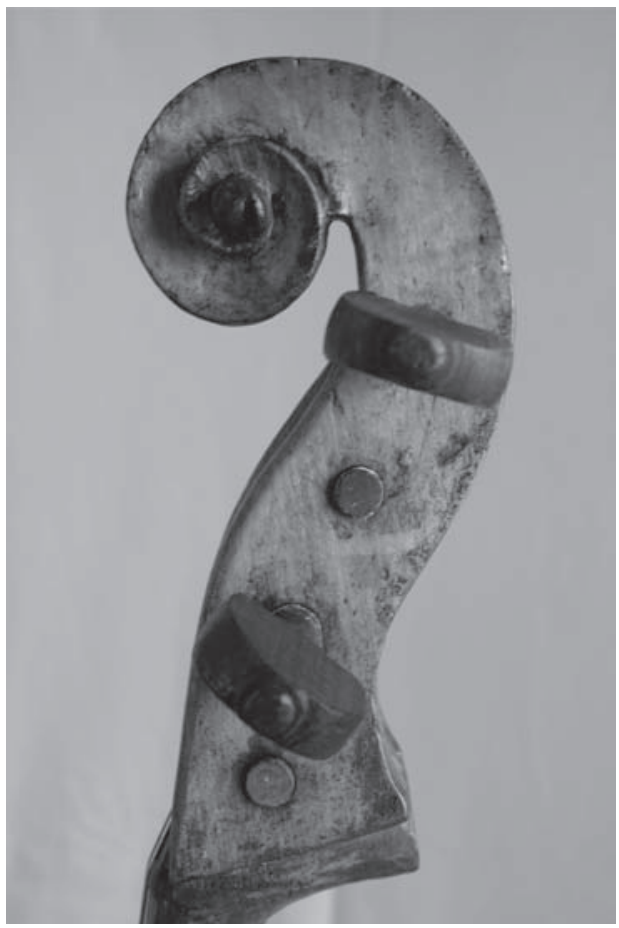

Figura 18. Vista derecha del clavijero.

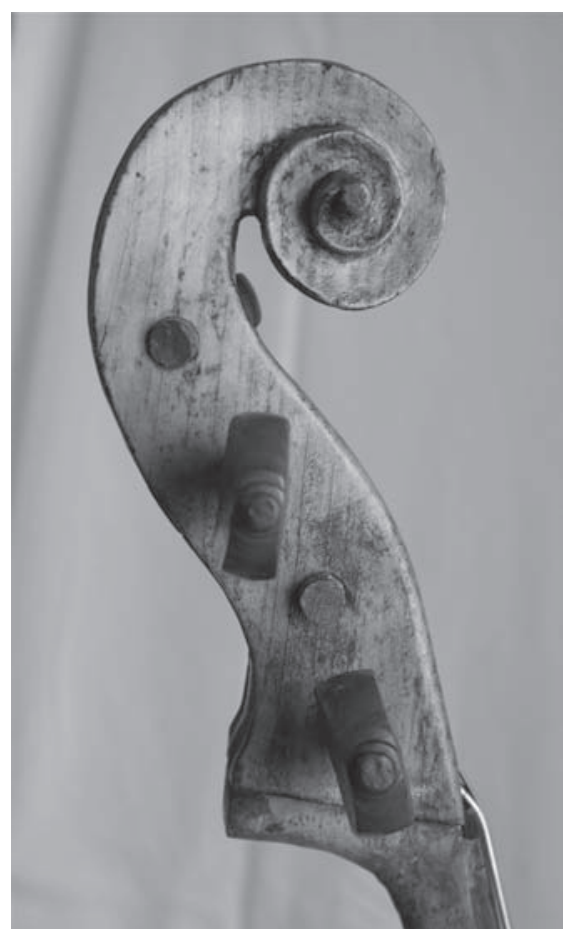

Figura 17. Vista izquierda del clavijero.

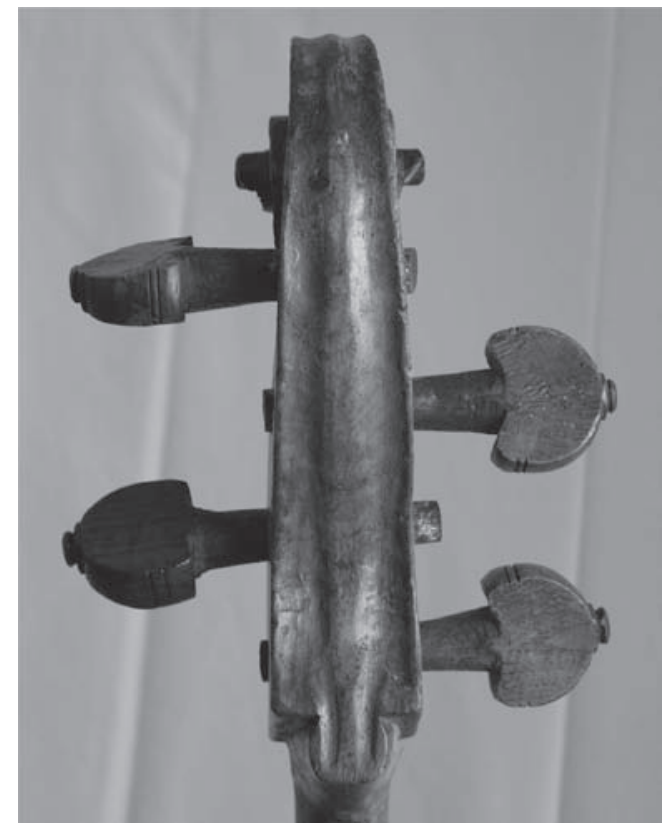

Figura 19. Vista trasera del clavijero. 


\section{Contexto}

La mayor parte de los instrumentos de cuerda españoles del sigløvIII que se conservan pertenecen a la segunda mitad del siglo y están construidos ya con las técnicas difundidas por los luthieres italianos en toda Europa.Algunos de ellos aún conservan algunas de las características de construcción española antigua pero han sido transformados en violonchelos modernos y es difícil apreciar en su totalidad cómo fueron concebidos. Los violonchelos que construyeron los violeros españoles o franceses que trabajaron en España tienen como referencia e imitan a los grandes luthieres italianos, sobre todo a Amati y Stradivarius. Así, una buena parte de los instrumentos del considerado como más importante de los violeros españoles, José Contreras (1710-1782), conocido como el Granadino, son magníficas copias de los de Stradi varius. A esta misma tradición pertenecen también su hijo José Melitón Contreras (1741-1791), Vicente Asensio ( $f$ l. 1773-1795), Nicolás Duclos, luthier francés asentado primero en Barcelona y luego en Madrid - hay que anotar que en su etiqueta firmaba como Discipulus Destradivarius-, el también francés Francisco Gand ( $f$ l. 1762-1795), Juan Guillamí (1702-1769) y su hijo del mismo nombre (1739-1819), Silv erio Ortega (1765-1846), José Narciso de la Vega (17361799) o el valenciano Manuel Senchordi (ca. 1700-1765) ${ }^{12}$. Instrumentos en los que perduran algunas de las características de la escuela "arcaica” son los de Salv ador Bofill (1705-1771), de gran tamaño y, en ocasiones, con la tapa compuesta de tres piezas de nogal, José Massaguer (1690-1764), que usa aún la técnica del zoque y sin contraaros y los dos violonchelos de Francisco Sanguino (t. 1750-1780) en Sevilla ${ }^{13}$.

El único ejemplar de violón perteneciente a la escuela de violería antigua española, en concreto la madrileña, con el que podemos compararlo directamente es el construido por Gabriel de Murzia en 1709 y que hoy se conserva en el Museo del Traje de Madrid ${ }^{14}$. En este caso se trata de un violón de grandes proporciones (79'5 cms. de caja) por lo que podríamos hablar de un bajo de violín ${ }^{15}$. Aún así podemos encontrar similares características de construcción con el de Román como el taco y el mástil hechos de una pieza (zoque), las juntas interiores reforzadas con lino y la ausencia de contraaros, la tapa de pino hecha en cuatro piezas y los filetes grabados y teñidos de negro.

Otra de las pistas a seuir en la definición de la tipología y sistema de construcción de los violones españoles sería la de los usados en las misiones jesuíticas de Sudamérica ${ }^{16}$.

Aunque la tipología del siguiente instrumento no tiene nada que v er con el violón de Domingo Román, sí que es importante ponerlos en relación porque la técnica de construcción corresponde

12 Ver Pinto Comas, Ramón: Los luthiers españoles. Barcelona, Ramón Pinto Comas, 1988;Els nostres luthiers. Escultors del so. Barcelona, Ajuntament de Barcelona, 1996.

13 GÁndara, Xosé Crisanto: "El violón ibérico", op. cit., p. 151.

14 Ver Bordas IbÁÑez, Cristina: "Instrumentos españoles de los siglos XVII y XVIII en el Museo del Pueblo Español de Madrid”, en Revista de Musicología, vil/2 (1984), pp. 301-303; “T radición e innovación...”, op. cit., pp. 201-218; Instrumentos musicales en colecciones españolas, op. cit., p. 178; PinTo CoMAs, Ramón: op. cit., p. 281; Els nostres luthiers. Escultors del so . Barcelona, Ajuntament de Barcelona 1996.

15 Ver BonTA, Stephan: "Corelli’s Heritage...", op. cit

16 Szarán, Luis: Música en las Reducciones Jesuiticas de América del Sur. Asunción, Fundación Paracuaria, 1999. 
a la misma tradición española. Se trata de la vihuela de arco de cinco cuerdas conserv ada en el Convento de la Encarnación de Ávila. Raf ael Pérez Arroyo publicó un artículo en el que describe sus características ${ }^{17}$ y medidas. Es difícil saber a qué tipo de instrumento corresponde. Que tenga cinco cuerdas lo coloca entre los violones, generalmente de cuatro, y las vihuelas de arco, de seis. No hemos de olvidar, sin embar go, que la estandarización a la que ho y estamos acostumbrados no siempre ha existido. No es muy descabellado referirse para el caso a las vihuelas de arco francesas de cinco cuerdas a las que hace referencia Jambe de Fer o a algunas anotaciones escritas en las cuentas del violero de la ReinaAntonio de Zulueta referentes a violones que se ponen de cinco órdenes porque eran de cuatro:

“[...] Cornelio Segre. Hásele dado al dicho una encordadura para el violón y un aderezo en el que era menester echarle los puntos y ponerle de cinco órdenes porque era de cuatro y aderezarle lo que tenía más que todo el aderezo y encordadura..."18.

Aunque, en este caso pero sin ninguna certeza, posiblemente se esté refiriendo a un contrabajo de violín. No es, sin embargo, esto lo que ahora nos concierne si no el hecho de que esta vihuela de arco participa de algunas de las características técnicas arcaicas de f abricación de instrumentos de cuerda, esto es, tapa en tres piezas de pino y trasera plana también de pino reforzadas con tiras de lino y el uso del nogal para el mástil. Hay que hacer notar que comparte elementos decorati vos, como los oídos en forma romboidal rematada por dos circunferencias, con el arpa de Domingo Pescador (arpista de la Seo de Zaragoza) del mismo Con vento de la Encarnación de Ávila y con la de Pere Elías del Museo Provincial de Ávila ${ }^{19}$.

El resto de los elementos de la violería española con que poder comparar los del violón de Román los tendremos que buscar en los instrumentos de cuerda pulsada, ya que salieron de los mismos talleres y se aplicaron técnicas muy similares. Por lo menos hasta finales del siglo XVIII e incluso bien entrado el XIX, los mismos violeros que fabricaban las guitarras se hacían cargo también de las vihuelas de arco y de la familia de los violones.Ya desde el primer reglamento del gremio de violeros conocido, impreso en Sevilla en 1527, se especifica que:

“[...] el oficial violero para saber bien su oficio y ser singular del, ha de saber $f$ azer instrumentos de muchas artes, que sepa hacer un cla viorgano y un cla vicimbano, y un monacordio, y un laud, y una vihuela de arco, y una harpa, y una vihuela grande de pieças con sus atarcees y otras vihuelas que son menos que todo esto $[\ldots]^{\prime 20}$.

17 Ver Pérez Arroyo, Rafael: op. cit.

18 Asenjo BARBIERI, Francisco: Documentos sobre música española y epistolario (Legado Barbieri). Vol. 1, Ed. a cargo de Emilio Casares Rodicio. Madrid, Fundación Banco Exterior, 1998, p. 513.

19 Bordas, Cristina: “Origen y evolución del arpa de dos órdenes", en Nassarre, v/2 (1989), p. 99.

20 Estudios sobre la Vihuela, op. cit., p. 158. 
Poco después se prohibirá e xpresamente que los maestros violeros tengan nada que v er con los instrumentos de tecla a los que sí están obligados en las ordenanzas de Se villa. Pronto, en 1590, aparecerá el término violón en las ordenanzas:

"que supiesen hacer una viguela llana una arpa y un violon de arco a modo e imitación de los estranjeros $[\ldots]]^{\prime 21}$.

Todo este despliegue de instrumentos de cuerda en los talleres se puede apreciar perfectamente en las cuentas que se conservan de los violeros que trabajaron en Madrid para la corte ${ }^{22}$.

No será esto extraño en el resto del continente ya que afamados constructores como Stradivarius también hicieron guitarras, eso sí, aplicando técnicas distintas a cada familia.

En España sí se compartieron las mismas técnicas. El elemento común a ambas $f$ amilias más generalizado es el uso del zoque, o sea, la construcción, en un solo bloque de madera, del cla vijero, mástil y el taco. Este apoya en la trasera y, en sendas ranuras practicadas en los bordes, van insertados los aros. Lo encontraremos por doquier en las guitarras y vihuelas conseadas. Así, lo podemos apreciar en la más famosa de las vihuelas que han logrado sobrevivir, la del Museo Jaquemart-André, atribuida a Juan de Guadalupe ${ }^{23}$. En este caso, toda la pieza está compuesta de un ensamblado de distintas maderas preciosas que forman un dibujo geométrico. También nos encontraremos con el zoque en las vihuelas E.0748 del Museo de la Música de París (en este caso de ciprés), la de Belchior Dias (Lisboa, 1581) guardada por el Royal College of Music de Londres ${ }^{24}$, la de Quito y así, de la misma forma en el futuro, constituyendo una de las principales características constructivas de las guitarras.

Aunque las tapas de vihuelas y guitarras necesitan menos madera que un violón, y no es, por lo general, necesario, podemos encontrar algún ejemplo de tapa compuesta por más de dos piezas como la de Guadalupe, que tiene tres piezas de madera de pinabete del sur de Alemania. Para la tapa armónica del violón de Román, al igual que la del de Murcia, se usaron cuatro piezas, también de pinabete. El uso de esta madera es, casi en cualquier sitio de Europa y momento de la historia de los instrumentos de cuerda, lo habitual. No constituye por tanto una e xcepción. Tampoco constituye una excepción el uso del arce para los aros pero sí el chopo o álamo para la trasera. Recordemos que el violón de Gabriel de Murcia es de sicomoro, una variante del arce.

En cuanto al resto de los materiales usados por Domingo Román podemos considerarlos comunes a los instrumentos españoles. El nogal macizo del batidor y del cordal lo podemos encontrar por doquier no sólo en instrumentos, sino también en el mobiliario. Es posiblemente, después del pino, la madera más usada en España entre los siglos XVI y XVIII. En este caso, sí podemos hablar de una excepción, ya que el material usado de forma habitual para la chapa del batidor (plantilla) y para el cordal era el ébano u otra

21 Romanillos, José Luis: "La construcción de la vihuela de mano y de la guitarra española en las ordenanzas y en los inventarios de taller de violeros y guitarreros españoles", en Estudios sobre la vihuela, op. cit., p. 114.

22 AsEnJo BARBIERI, Francisco: op. cit.

23 Dugot, Joel: "La vihuela del Musée Jacquemart-André", en Estudios sobre la vihuela, op. cit., pp. 85-95.

24 GonzÁlez, Carlos: "La vihuela E.0748 del Musée de la Musique de París”, en Estudios sobre la Vihuela, op. cit., pp. 97-111. 
madera dura, tanto en España como en el resto de Europa. Sí que lo v eremos, sin embargo, en algunas tapas, aros y traseras de violones posteriores como los de Guillamí, Bofill o Massaguer, todos ellos catalanes, en costillas de guitarras o en arpas. Así, en las ordenanzas de violeros de Toledo de 1617:

“un arpa de dos ordenes con costillas y brazo y caveza de nogal todo [... $]$ ”25.

Un buen ejemplo de esto lo podemos v er en el arpa de Juan López, (T oledo, ss. XVII-XVIII) en la que, exceptuando la tapa que es, obviamente, de pino, es toda de nogal ${ }^{26}$.

La madera del mástil y clavijero del violón de Román es más difícil de identificar. Se trata de una madera clara y de escasa dureza. Podría tratarse de chopo o álamo. No son materiales muy habituales en los instrumentos pero sí maderas muy presentes en España. Podemos encontrar referencias a arpas hechas de álamo blanco. En relación a esto, leemos en las cuentas del violero madrileño del siglo XVII Antonio Hidalgo:

"Una harpa grande de dos órdenes de álamo blanco perfilada de ébano y marfil con cinco viriles en los lazos con molduras de ébano, que la hizo Antonio Hidalgo, violero [...]"27.

"Una arpa de álamo blanco y nogal perphilada de ébano de a tres con zinco lazos en el arca [...]"28.

Otra de las técnicas empleadas por Román transferida de los instrumentos de cuerda pulsada es la de doblar los aros o costillas en caliente. La escuela italiana de luthería establece que se tallan sobre un taco de madera y se montan sobre un molde. En ocasiones se pueden apreciar en los aros marcas de quemaduras hechas con hierros candentes con el fin de doblarlos. Así, la vihuela E.0748 del Musée de la Músique de París presenta quemaduras en los aros. Las costillas acanaladas pueden haber sido dobladas también en caliente, pero al vapor ya que no presentan signos de quemaduras ${ }^{29}$. Los aros de nuestro violón siguen la técnica del cepillado y doblado con hierros candentes.

Cuando lo habitual en un violonchelo es que la unión de la trasera con los aros se refuerce con unas tiras de madera llamadas contraaros, el violón de Román no los tiene y sí, sin embar go, unas largas tiras de lino o cáñamo. Esta técnica será también la usada por los guitarreros. Sirv an, como ejemplo, esta cita sacada de las ordenanzas de violeros de Toledo de 1617:

"Yten que qualquiera biguela de qualquier calidad que sea lle ve la madera bieja que es suelo y cuello de pino con tapa de pina vete y no de otra madera alguna y baya aforrada por la parte de a dentro con tres lienços en cada costilla de quatro dedos de largo pena de mill maravedis lo que en contrario desto se hiciere aplicados según dicho es"30.

25 Ver en las “Ordenanzas de violeros, Toledo, 1617”, en Estudios sobre la vihuela, op. cit., p. 177.

26 Bordas, Cristina: Instrumentos musicales en colecciones españolas, op. cit., pp. 204 y 205.

27 Ver cuenta de 31.01.1615 [Biblioteca Nacional, Fondo Barbieri, Mss. 14043 (153-155)].

28 Ver cuenta de 14.12.1616 (Archivo General Palacio Real, Madrid,Admva. Leg 902). Estas dos últimas citas las tomamos de Bordas, Cristina: "Origen y evolución del arpa...", op. cit., p. 93.

29 GonzÁlez, Carlos: "La vihuela E.0748...", op. cit., p. 103.

30 Ver en las “Ordenanzas de violeros, Toledo, 1617”, en Estudios sobre la vihuela, op. cit., p. 178. 
y las palabras de Nasarre sobre las arpas:

"Y por la parte interior se ha de encolar en cada junta una lista de lienço de e xtremo à extremo, que tenga un dedo de anchura, para que queden mas unidas las piezas, y que quede el concaro mas solido: ha de ser de lienço fuerte, y no importa mas que sea lino, ò cañamo; pero no puede ser lana, porque no serà resonante el instrumento. Asi nos lo enseña Aristóteles diziendo: No hay sonido en la lana"31.

Si esta era la forma de cerrar la trasera, la tapa se montaba mediante unos pequeños tacos. En el violón de Román encontramos tacos similares a modo de peones de distintas épocas por lo que, suponemos, la reparación o reparaciones fueron hechas también por guitarreros. Los podemos v er como refuerzo de las barras en la vihuela del Museo de la Música de París.

A pesar del carácter tosco de nuestro instrumento, tiene un elemento decorati vo que lo hace especialmente atractivo. El corto batidor de nogal tiene insertadas, en disposición longitudinal y en el centro, una serie de placas de hueso que lo relacionan directamente con el trabajo de incrustaciones y taraceas de los guitarreros. Buena parte de las guitarras y vihuelas conserv an elementos decorati vos de este tipo y, casi siempre, mucho más complejas. No es habitual encontrar decoraciones de hueso o marfil o taraceas en instrumentos de la fimilia de los violines pero sí en algunas violas da gamba. Nos gustaría poder comparar el violón con alguna vihuela de arco española contemporánea pero, por desgracia, no se conserav ninguna, que se sepa. Y si buscamos en siglos anteriores al XVIII, nos queda la vihuela de arco de Ávila csi es que se puede considerar como tal-, la iconografía -ver, por ejemplo la vihuela de arco de Xátiva- y un buen número de referencias documentales. Así, y centrándonos sólo en el asunto de las taraceas, podemos encontrar esta referencia en el inventario de Madrid de 1602, versión revisada del de 1597:

"Cinco vihuelas de arco de madera blanca con unos cuadros samblados de taracea de mano de Dominico en tres caxas" 32 .

Luis Robledo ${ }^{33}$ supone que estas vihuelas pudieran ser las mismas que Isabel Sánchez Coello, hija del pintor Alonso Sánchez Coello, vendió en 1591 al príncipe Felipe -futuro Felipe III-. Siempre ha llamado mucho la atención este hecho y , por la estrecha relación entre Alonso Sánchez Coello y El Greco, habitualmente se ha supuesto que las taraceas podían haber sido obra de este último. No vamos a entrar en profundidad ahora en este tema, pero sí que nos gustaría destacar dos preciosos violas, supuestamente v enecianas, atrib uidas a Domenico Russo y conserv adas en el Ashmolean Museum de Oxford y en el Tiroler Landesmuseum Ferdinandeum de Innsbruck ${ }^{34}$, que presentan una serie de taraceas de estilo morisco similares a las de las de la vihuela de Guadalupe, aunque algunas

31 Nassarre, Pablo: Escuela Música según la práctica moderna. Zaragoza, Herederos de Die go de Larumbe, 1724. Ed. Facsímil, Zaragoza, IFC, 1980, p. 459.

32 Asenjo Barbieri, Francisco: "Documentos...", op. cit., vol. 2, p. 74.

33 Robledo, Luis: "Vihuelas de arco y violones...", op. cit., p. 66.

34 Herzog, Myrna: "Violin Traits in Italian Viol Building, Rule or Exception", en The Italian Viola da Gamba. Proceedings of the Internacional Symposium on the Italian Viola da Gamba. Susan Orlando, ed. Solignac y Turín, Angolo Manzoni, 2002, pp. 153-156. 
de las de este instrumento no sean originales. Ciertamente, siguen el mismo diseño que algunas violas de Gasparo da Salò y otros constructores brescianos por lo que la atrib ución a esta escuela parecía evidente. Pero Benjamín Hebbert plantea la posibilidad de que estas dos violas sean españolas y que influenciaran posteriormente a las brescianas ${ }^{35}$. Hebbert encuentra, además, otras cone xiones con los instrumentos españoles como la trasera de nogal, la madera de las tapas distinta a la de los italianos, la mayor cercanía de la talla de la cabeza del ejemplar del Ashmoleum a modelos españoles que a italianos y la desproporción en relación a los brescianos. No parece descabellado, por tanto, pensar que estas vihuelas de arco con taraceas de Domenico Russo sean muy similares a las que aparecen en el in ventario de 1602. Esta misma tipología de viola da gamba la encontramos en instrumentos de Gasparo da Salò y , curiosamente, en el cuadro de la Anunciación de El Greco conserv ado en el Museo del Prado y en sus dos bocetos preparatorios del Museo Thyssen y del Museo de Bellas Artes de Bilbao. Están pintadas con gran detalle y realismo y no es difícil relacionarlas con las conocidas de Gasparo da Salò. Hebbert, nuevamente, nos remite a Hill que dice que compró a la Catedral de Bugos la viola de Gasparo da Salò que ahora obra en poder del Ashmolean Museum ${ }^{36}$. Ciertamente, parece el mismo instrumento que el pintado por El Greco.

Siguiendo la pista de las influencias europeas en los instrumentos españoles y, por tanto, en el de Román, volvemos a los violones pero seguimos, por el momento, en Italia. La primera noticia conocida de músicos de violones en España es la referida a los que trajo en su séquito la tercera esposa de Felipe II, la francesa Isabel de Valois ${ }^{37}$. Aunque en los documentos aparecen con los nombres a la francesa o a la española, se sabe que eran italianos. De hecho, en la relación aparecen denominados como violons, el término francés, pero ellos firman como violoni. No se sabe qué instrumentos traían consigo pero sí se conocen instrumentos de Andrea Amati en los que están representadas las armas de Felipe II. Quizá formaran parte de un encargo hecho a Amati por Catalina de Medici, madre del futuro Carlos IX de Francia e Isabel de Valois como regalo a su yerno, Felipe II, con motivo de la boda entre estos dos últimos en 1560. Así, por ejemplo, la violetta de Amati que posee el Musée de la Musique de Paris presenta en su trasera una pintura con las armas del re y Felipe II. El violín del Metropolitan Museum también pertenece, supuestamente, a este encargo ${ }^{38}$.

Las referencias tanto a músicos como a instrumentos italianos en España en los siglos XVI y XVII son numerosas. Además de la viola da gamba de Gasparo da Salò antes citada de la Catedral de Bugos, podemos

35 Hebbert, Benjamin: "Brescia: Influence and Influences in Spain and Italy", en Gaspar da Salò, architetto del suono . Flavio Dasseno, ed. Cremonabooks, 2009.

36 HiLl, Arthur F., et al.: An Illustrated Catalogue of the Music Loan Exhibition held under the patronage of His Majesty the King, Her Majesty the Queen, and their Royal Highnesses The Prince and Princess of Wales by the Worshipful Company of Musicians at Fishmonger's Hall, June and July, 1904. Londres, Novello and Company, 1909. Citado en HebBert, Benjamin: Op. cit.

37 Ver Robledo, Luis: "La música en la Casa de Isabel deValois", en Aspectos de la cultura musical en la Corte de Felipe II, op. cit., p. 200; "Vihuelas de arco y violones...", op. cit., pp. 63-76.

38 Sobre la controversia en torno a los instrumentos deAndrea Amati supuestamente encargados por Carlos IX, ver LESURE, François: "La commande à André Amati: parcours d'une légende obstinée" y MoEns, Karel: "Analyse des instruments conservés", en Musique, Images, Instruments. Revue française d'organologie et d'iconographie musicale. París, $2003, \mathrm{n}^{\circ} 5$. 
encontrar referencias alcontrabaxo grande de Florencia en que se tañen las lamentaçiones?, las reparaciones o adaptaciones hechas a los violones de los músicos italianos por los distintos violeros de la reina (er lo antes referido a Cornelio Segre) y el ingente número de violones y tañedores de vihuela de arco al servicio de los príncipes, reyes y reinas de España, desde Melchor Cáncer hasta Domingo Porreti, pasando por Mateđroilo, padre e hijo, Thomas Gallo o Pedro Esterlic. Por cierto, de este e xiste una curiosa caricatura de Ghezzi de 1742 en la que aparece, ya de vuelta a Italia, tocando un violonchelo pero con la técnica de arco de la viola da gamba ${ }^{40}$. Pronto empezarán a lle gar los instrumentos de moda: Stradi varius, Amati, Stainer y, con ellos, la revolución y paulatino abandono de las antiguas técnicas. Mientras en Madrid Antonio de Literes ${ }^{41}$ tocaba un violonchelo de Stradivarius, Domingo Román estaba construyendo nuestro violón en Valladolid ${ }^{42}$. Era el momento de transición entre la antigua tradición y las nuevas modas de la modernidad.

Son pocos los datos que tenemos acerca de las huellas dejadas por la luthería bresciana y cremonesa en España pero, por las características que conocemos de los instrumentos conserv ados, parece que tenemos que b uscar en otros ámbitos geográficos para encontrar puntos en común con la antigua tradición española a la que pertenece el violón de Román. Tampoco encontraremos muchas influencias de los violones de la China a pesar de las enigmáticas referencias a

"Cuatro biolones grandes, mediano y pequeños que van disminuyendo en grandor, hechos en la China, son de madera laqueada y la tapa de madera amarilla [...]".

"Cinco biolones grandes de la China, laqueados de oro y negro con las tapas de madera blanca dorada a partes $[\ldots] " 43$.

Evidentemente, y a diferencia de lo que ocurre ho y en día, es difícil pensar en violones hechos realmente en China a finales del s. XVI.

Así, para hacer un análisis completo de las influencias de las distintas escuelas europeas, tenemos que pasar a hacer referencia a la flamenca y a la del sur de Alemania.

Las citas a instrumentos - de todas las f amilias- flamencos o alemanes en la documentación española de los siglos XVI y XVII son frecuentes. Si nos remitimos al documento en el que aparece la primera mención a los violones en España,

"çinco violones de arco, que llaman de braço, con sus arquillos [...]"44.

39 RoBledo, Luis: "Vihuelas de arco y violones...", op. cit., p. 67.

40 LA VIA, Stefano: fig. 15. Op. cit. en Estudi Corelliani IV.

41 Álvarez Solar-Quintés, Nicolás: “Antonio Literes Carrión y sus hijos (nue vos documentos para su biografía)”, en Anuario Musical, v (1950), pp. 169-189.

42 Para los nuevos instrumentos italianos en España, v er Bordas, Cristina: "De violero a guitarrero...", op. cit., p. 137; Fonseca SÁnchez-JARA, Elisa María: "Composturas y otros encargos en los instrumentos de cuerda de Carlos IV Príncipe (17601788)", en Reales Sitios, 179 (2009), pp. 42-57; Siemens HernándEz, Lothar: "José García Marcellán: historia de los instrumentos de música construidos por Stradi varius y Amati que en la actualidad posee la Real Capilla de S. M. (Madrid, 1919)”, en Revista de Musicología, 8/1 (1985), p. 149; Hill, Henry W.; Hill, Arthur F.; Hill, Alfred E.: Antonio Stradivari His Life and Work (16441737). Londres, Constable and Company, Ltd., 1902. Reimp. Nueva York, Dover, 1963.

43 Ver los inventarios y tasación de 1597 y de 1602 en AsENJo BARBIERI, Francisco: op. cit., vol. 2, pp. 70 y 74.

44 Bordas, Cristina: "E cosas de música: Instrumentos musicales en la Corte de Felipe II", en Aspectos de la cultura musical en la Corte de Felipe II. Luis Robledo, Tess Knighton, Cristina Bordas, Juan José Carreras, eds. Madrid, Fundación Caja Madrid (Colección Patrimonio Musical Español), 2000, p. 219. 
en el in ventario de 1559 de los bienes de María de Hungría (1505-1558), hermana del emperador Carlos v, veremos que, junto a estos, aparecen dos conjuntos de siete y seis "vihuelas de arco hechas en Alemania" $"$. De momento es mucho suponer, pero quizá los violones de este mismo inventario los trajera María de Hungría de su Flandes natal y en el que había sido Gobernadora durante 24 años.

En cuanto a las ordenanzas del gremio de violeros, podemos encontrar dos interesantes noticias. Se refieren a los instrumentos que tiene que construir un aprendiz para obtener la maestría; en el primero de los casos, (ya citada anteriormente) en las ordenanzas de Madrid de 1584:

"un biolón de arco a ymitación de los estrangeros".

y en el segundo, en las de 1587:

"una vigüela de arco a imitación de las de Flandes"

Ambas citas son ambiguas y de difícil interpretación. Con sólo estos datos es imposible saber a qué biolones estrangeros se puede referir... ¿italianos, flamencos? La segunda da más pistas, por lo menos en lo referente al origen del modelo, pero no podemos saber si suponía una e xcepción que se imitara el modelo flamenco o una re gla. Si nos fijamos en la amplia iconografía de los P aíses Bajos y Holanda en el siglo XVII y comienzos del XVIII encontraremos numerosos bajos de violín en los que, aunque no se pueda decir , ni mucho menos, que sean iguales al violón de Román, sí que apreciamos similitudes: mástil corto, puntas de la caja muy pronunciadas, cla vijero y cla vijas de grandes proporciones...

Y si vamos directamente a los instrumentos conserados, veremos que sí, que realmente comparten características. Por ejemplo, los violones de Gaspar Borbon (Bruselas, ca. 1635-Bruselas, 1710) están construidos sin molde, según la costumbre flamenca, "en l'air" en palabras de Mia Awouters" ${ }^{47}$ Gaspar (o Jaspar) Borbon pertenecía a una familia de luthieres y músicos flamencos, posiblemente de origen español. Un tal Pedro Bourbon aparece entre los Ynstrumentistas y como maestro de violones en una lista del personal de la Capilla Real de Bruselas publicada por Van der Straeten, se gún cuenta Mia Awouters. Aunque hay localizados dos constructores del mismo nombre y, posiblemente, de la misma familia, es el mismo "Pietro Borbone, M[aest]ro de hazer instrumentos de mussica" que aparece más tarde, en 1648, en una orden de pago.

De todas estas características "arcaicas" y sobre todo, distintas a las italianas, de los instrumentos flamencos ha escrito el investigador Karel Moens:

“Le manche n’est pas collé mais entre dans le corps. Les éclisses sont collées dans une rainure qui

45 Bordas, Cristina: “E cosas de música...”, op. cit., p. 220; Asenjo Barbieri, Francisco: op. cit., vol. 2 , pp. 70 y 74.

46 BoRDAs, Cristina: "De violero a guitarrero...", op. cit., pp. 132-133.

47 Awouters, Mia: "Borbon, Gaspar", en Dictionnaire des facteurs d'instruments de musique en Wallonie et à Bruxelles du 9e siècle à nos jours. Malou Haine, Nicolas Meeùs, eds. Bruselas, Editions Mardaga, 1986, p. 61 . 
longue le contour du dos et leurs extrémités supérieures sont fixées dans deux rainures du manche... Sur les quatre coins, les extrémités des éclisses sont collés en biseau les unes aux autres au lieu d'être liées avec une pièce de bois, du papier ou du parchemin. Les courbes des renforts de la table et du dos sont travaillées dans la masse"

Por último citaremos un violonchelo de J. Delanno y (Bruselas, 1780) del que, nuevamente, Mia Awouters nos describe las mismas características, añadiendo la tapa de $\mathrm{v}$ arias piezas, montado $\sin$ molde, sin contraaros ni refuerzos en las esquinas, la asimetría y materiales como el plátano (quizá arce sicomoro) y el nogal ${ }^{49}$.

Resumiendo: taco y mástil de una pieza; aros incrustados en el taco del mástil y en la trasera, esquinas puntiagudas, aros doblados con calor y montados sin molde, junturas reforzadas con papel o pergamino y sin contraaros... No podemos negar el parecido de los instrumentos flamencos con lo que conocemos de los españoles.

Otra de las escuelas europeas es la correspondiente a algunas zonas del sur de Alemania y de Suiza que han estudiado Anette Otterstedt y Olga Adelmann en su libro Die Alemannische Schule ${ }^{50}$. En él podemos v er bajos de violín de cinco cuerdas, con una profusa decoración y , lo que es más importante y comparable al violón de Román, zoques y tapas con la barra armónica tallada en la misma pieza de madera. En este caso ocupan todo el lar go de la caja y están situadas, aproximadamente, en el centro. En cambio, la barra de Román es corta y situada en un lateral. Aún así, pertenecen las dos formas de barra armónica a la que venimos llamando técnica "arcaica".

Todo lo escrito anteriormente formaría parte de un trabajo más e xtenso y a desarrollar , que intentará contribuir al mejor conocimiento de las características de la escuela española de la violería referida a los violones y vihuelas de arco y su entronque con los instrumentos españoles de cuerda pulsada y los de otras escuelas europeas como la flamenca, del sur deAlemania o inglesa, conformando una escuela europea, posiblemente anterior y diferente de la italiana que posteriormente se establecería como canónica en todo el mundo.

Recibido: 20/08/2009

Aceptado: 03/09/2009

48 Moens, Karel: "V ioles ou violons", en Musique, Images, Instruments . P arís, Re vue Française d'Or ganologie et d'Iconographie Musicale. 1996, nº 2, p. 21. Hace también partícipes de esta técnica a bena parte de las violas da gamba europeas de la segunda mitad del s. XVI y del XVII. Del mismo autor, ver: Instruments à cordes frottées, 3. Bruselas, Musée des instruments de Musique, ed. Mardaga, 2000, p. 9. Ver foto del taco del mango de un violín en ilust. 4, p. 8.

49 Awouters, Mia: "Les instruments à cordes", en Instruments de musique anciens à Bruxelles et en Wallonie . Malou Haine, Nicolas Meeùs, eds. Bruselas, Editions Mardaga, 1986, pp. 13-18. En la p. 14 se puede apreciar una foto de la huella del mango en la trasera del violonchelo de Delannoy.

50 Otterstedt, Anette y A delmann, Olga: Die Alemannische Schule. Geigenbau des 17. Jahrhunderts im südlichen Schwarzwald und in der Schweiz . Berlín, Musikinstrumenten-Museum Stiftung Preussischer K ulturbesitz, 1997; O TTERSTEDT, Anette: "What Old Fiddles Can Teach Us...", en The Galpin Society Journal, 52 (1999), pp. 219-242. 